\title{
Androgenic Activity Evaluation of Ginger Rhizome in Reducing Depression in the Forced Swimming Test of Rats Exposed to Electromagnetic Field (EMF)
}

Arash Khaki ${ }^{1 *}$, Alireza Farnam ${ }^{1}$, Samaneh Rouhani ${ }^{1}$, Bahram Imantalab $^{2}$, Saeed Seery ${ }^{2}$

Article History:

Received April 2013

Accepted May 2013

Available online September 2013

\section{Keywords: \\ Depression \\ Electromagnetic Field \\ Forced Swimming Test \\ Ginger Rhizome}

\section{Corresponding Author:}

Arash Khaki, Clinical Psychiatry Research Center, Tabriz University of Medical Sciences. Tabriz, Iran. Tel: +989143138399

Email: arashkhaki@yahoo.com

\begin{abstract}
Objective: Ginger has always been known as one of the most famous medicinal herbs in eastern Asia (China and India). In this study we examined the effects of antidepressants-like activity of Ginger on the protection of central nervous system against oxidative damages.

Material and Methods: Male Wistar rats $(n=30)$ were allocated into three groups, control $(n=10)$ and test groups $(n=20)$ that subdivided into groups of 2 that had been exposed to $50 \mathrm{~Hz}$ electromagnetic fields (EMFs) for 8 weeks, one of the test groups received Ginger rhizome powder $(1.5 \mathrm{~g} / \mathrm{kg} /$ day. body weight) for 8 weeks as well. In the second and eighth weeks, we used forced swimming test in order to evaluate the antidepressant effect of Ginger powder on the rats exposed to EMF.

Results: In the second week results revealed EMF exposure increase immobility but decrease loco-motor function of swimming and climbing in comparison to control group $(\mathrm{P}<0.05)$ whereas at the end of 8th week, rats that had been fed with Ginger powder (1.5 g g/kg/day .body weight) showed decrease in immobility score and increase in swimming $(\mathrm{P}<0.001)$, but not in climbing scores significantly. $(\mathrm{P}=0.18)$. Conclusion: Ginger powder could act as serotoninergic antidepressant medicine in order to decrease depression presentation in exposed subjects to EMF.
\end{abstract}

1. Clinical Psychiatry Research Center, Tabriz University of Medical Sciences. Tabriz, Iran.

2. Department of Veterinary Pathology, Tabriz Branch, Islamic Azad University, Tabriz, Iran. 


\section{Introduction:}

Nowadays use of equipment that generates electromagnetic has greatly expanded. One of the most common electromagnetic devices is mobile phone, so both epidemiological and experimental studies have been motivated. Damaging effects of microwave radiation that electromagnetic devices release have been indisputably reported that is alarm for today's society. Exposure to electromagnetic field (EMF) at even low frequencies (900 to $1800 \mathrm{~Hz}$ ) causes some established pathological consequences such as increased permeability of the blood-brain barrier, disturbed neurons function and alteration in electroencephalography (EEG), disturbed regional cerebral blood flow, oxidant and antioxidant imbalance, neurotransmitter imbalance and genomic responses $(1,2)$.

One of the mechanisms that may be involved in cell injury is Cellular oxidation and free oxygen radicals which are accompanied with cognitional and effective sequences (3). Number of anti-oxidative substances in following hypotheses are introduced which protected central nervous system against the oxidative effects of EMF.

The use of protective agents against environmental risk factors is in the early stages. Since herbal-based medications are accompanied with lower imposed side effects, they have been motivated (4).

Ginger rhizome (Zingiber officinale R., family: Zingiberaceae) is used worldwide as a spice. Both anti oxidative and androgenic activity of Z. officinale were reported in animal models. All major active ingredients of Z. officinale, such as Zingiber, Gingerol, Zingibrene, gingerols and shogaols, have antioxidant activity. Besides, other researches showed that Ginger oil has dominative protective effect on DNA damage induced by $\mathrm{H} 2 \mathrm{O} 2$ and might act as a scavenger of oxygen radical and might be used as an antioxidant.

Recent study by Khaki et al (2009) showed that Ginger could increase sperm health parameters and protect exposed animals by EMF. The objective of this research was to see the modulating effect of Ginger on depression that is induced by EMF (5).

\section{Material \& Methods:}

\section{Animals}

Male albino Wistar rats, 8 weeks of age (weight $=220 \pm 10 \mathrm{~g}$ ) were housed in standard cages $(14 \times 9 \mathrm{~cm}$ cages $)$ inside a well-ventilated room kept at $20 \pm 2{ }^{\circ} \mathrm{C}$ with 12-h dark-light cycle. They were obtained from Tabriz Medical Science University Central Animal Facility, and were kept in Dr. Khaki laboratory. All animals had free access to a standard pellet diet and water.

Animals were exposed to radiation from experimental field $(0.1$ Tesla) for $6 \mathrm{~h}$ continuously per day for 8 weeks. Animals were free to move in the cage during the exposure period. Sufficient ventilation and avoidance to impose heat shock to rats was controlled. Rats were brought back to the home cages following exposure. All interventions had been done during constant time period of 8:00 to 13:00. Animals were divided into three groups: group I $(n=10)$ control group (no exposure to EMF without Ginger feeding), group II (n $=10$ ) (exposure to EMF without Ginger feeding) and group III $(\mathrm{n}=10)$ (exposure to EMF with Ginger feeding). All the experiments were performed in accordance with the European Animal Ethics Committee.

\section{Forced Swimming Test :}

The modified forced swimming test was designed and used in accordance with the procedures described (6).

Rats were taken and placed individually in a cylinder $(50 \times 20 \mathrm{~cm})$ filled to a depth of 30 $\mathrm{cm}$, by fresh, non-choleric water $\left(22 \pm 2^{\circ} \mathrm{C}\right)$. During the $5 \mathrm{~min}$, the climbing, swimming and immobility behaviors were recorded at $5 \mathrm{sec}$ intervals. Two swim sessions were conducted: a 15 min pretest, followed $24 \mathrm{~h}$ later by a 5 min test. The 5 min test sessions were videotaped and viewed at a later time by two raters blind to treatment. The raters have scored rat behavior for each $5 \mathrm{sec}$ period (60 times for the $5 \mathrm{~min}$ test) as one of the following: (1) immobility, making only those movements necessary to keep its head above water; (2) swimming, making active swimming movements; and (3) climbing, making vigorous movements with the forepaws in and out of the water, usually against the cylinder. 
Tests were done in the second week and were repeated at the end of the study at the 8 th week to evaluate acute and chronic effect of powder of Ginger.

Extract Preparation :

Ginger root was bought from Local traditional market, Tabriz, Iran. Roots were changed to powder by mixture in Islamic Azad University, Tabriz, Iran.

\section{Drug Administration :}

Prepared powder was dissolved in aqua's water. Exposed rats were fed with Ginger powder as $1.5 \mathrm{mg} / \mathrm{kg}$ body weight by nasogastric tube. Feeding was done at least $1 \mathrm{hr}$ before exposure to electromagnetic field.

\section{Sucrose Preference Test :}

We had added standard sucrose consumption prefer test to our experiment to confirm depression presentation after exposure to electromagnetic fields.

For the sucrose preference testing, all animals were presented with two bottles in their home cages. One bottle contained normal tap water and the second one $10 \%$ sucrose solution. Consumption rates were recorded every hour over a $3 \mathrm{hr}$ period. Sucrose was offered $1 \mathrm{hr}$ after daily feeding. Sucrose intake was expressed in relation to the animal's body weight $(\mathrm{ml} / \mathrm{kg})$. Test was carried as a base score before exposure in both groups and would be repeated at the second and eighth weeks.

\section{Statistical analysis :}

The data were analyzed by SPSS software (version 17). The number of time points where climbing, swimming or immobility was scored over the $5 \mathrm{~min}$ experimental session were summed for each rat. Data were expressed as means with standard error of mean (SEM). The means of measures in two groups were compared by independent- $T$ test. Analyses of detected scores in behavioral parameters were done by one-way ANOVA test followed by Tukey's highest significant difference (HSD) test. $\mathrm{P}$-value $<0.05$ was considered significant.

\section{Results:}

In the second week of the study, it was found that EMF exposure affected all parameters of forced swimming test, as it significantly increased immobility and decreased loco- motor function of swimming and climbing in comparison to control group $(\mathrm{P}<0.05)$

feeding with Ginger didn't show any efficient radiation protection imposed stress (Figure 1) but in last week of experiment it was found that Ginger powder could be effective in decreasing immobility $(\mathrm{P}<0.001)$ and in increasing swimming $(\mathrm{P}<0.001)$; however, it had not affected the climbing behavior significantly $(\mathrm{P}=0.18)$ (Figure 2).

The Tukey's multiple comparison between control $(\mathrm{P}<0.01)$ and exposed group without Ginger feeding $(\mathrm{P}<0.01)$ showed that Ginger powder in chronic Stress (end of 8th week) had significantly decreased the total counts of immobility and Exposed animals had lower sucrose consumption in comparison to control group.

\section{Discussion:}

One of the most important ways to identify new antidepressant drugs are animal models $(7,8)$. The most common method used for the detection of antidepressants in animals is forced swimming test (FST) that was proposed primarily $(9,10)$ and was subsequently improved $(6,11)$. Eventually in test, it was observed that rodents develop immobility when they are placed in cylinder of water after they stop active escape behaviors, such as increased the score of swimming behavior significantly climbing or swimming. The use of antidepressants in the treatment reduces immobility, or delays its onset, and increase or prolong active escape behaviors displayed during the FST. Our experiment showed that exposure to electromagnetic fields is the cause of stress in animals that is followed by depression like behavior in exposed animals. The FST is the most widely used pharmacological model for assessment of potential antidepressant activity in rodents. Increased immobility factor in forced swimming test is an indicator for depression like condition in animal. However, to exclude stress imposed by FST, we have carried out another standard test to evaluate depression in exposed animals. Sucrose preference test is a standard test that confirmed our hypothesis. Decreased sucrose consumption preference predicates anhedonia, the major component of depression in animals. 
Experiments has shown that swimming score is sensitive to serotonergic compounds, and that climbing test is sensitive to drug with selective effects on noradrenergic transmission (12). Increasing swimming without significant increase in climbing like serotonergic agents predicts sedative effect of Ginger without stimulatory effect on loco-motor activity. However, true mechanism of antidepressant effect of the Ginger rhizome is still unknown but behavioral parameters in forced swimming test confirmed potential antidepressant effect as serotonergic agents. Our investigations showed Unlike serotonergic pharmaceutical medicines, Ginger powder have not got serious side effects as sexual dysfunction or restlessness since our study have manifested that Ginger powder has antianxiety effects. Khaki et al. (2011) have shown that nourished animals with Ginger powder had showed elevated level of testosterone and increased sexual desire as more sexual intercourse episodes (5). Mood disorders have been treated with botanical medicines since antiquity while modern researches on herbal medicine in psychiatry, although, still in their infancy, have increased in recent years with a 50\% increase in the literature (13). Some antidepressant herbal medicine, such as Hypericum perforatum, Rhodiola rosea (roseroot) and Crocus sativas (Saffron) offer promise for the treatment of depression via known psychopharmacological actions and sometimes antidepressant mechanisms are not as clearly defined as with selective serotonin reuptake inhibitors (SSRIs) (1425).

Some agents, such as Piper methysticum and $\mathrm{H}$. perforatum in meta-analyses studies revealed significant effects over placebo and comparable effects to synthetic agents (26). Herbal agents have better tolerability over some conventional antidepressants $(27,28)$. Although there are many non-tried herbal agents in traditional medicine of nations, these results and findings are encouraging. $\mathrm{H}$. perforatum is one of the mentioned herbal medicines that has been known as an antidepressant herbal medicine since several years ago and its efficacy was evaluated by several experimental studies (29). Ishola et al. (2008) investigated antistress efficacy of extract of Alchornea cordifolia in rats by occupying forced swimming test (30).

Hosseinzadeh et al. (2007) investigated antidepressant effect of Kaemperol, a constituent of Saffron (Crocus sativus) on rats. Entirely, the present study has showed that Ginger rhizome powder has had protective effect on depressed animals by electromagnetic fields (31). We suppose that protective property of Ginger against EMF is referred to its antioxidative potency and free radical scavenging activity. Some previous studies have investigated Ginger antioxidative property in vital organs $(3,32)$. The anti-oxidative effect is mainly due to phenolic components, such as flavonoids, phenolic acids and phenolic diterpenes. The antioxidant activity of phenolic compounds is mainly due to their redox properties, which can play an important role in absorbing and neutralizing free radicals, quenching singlet and triplet oxygen, or decomposing peroxides (33). Comparing the mentioned studies with our study showed similar results in their efficacy. Nonetheless, Ginger is a non-expansive material in general population with less probable hazardous side effects that people have used since several hundred years ago and it is acceptable in folklore culture with perfect favor in food. Fixed dose of feeding extract, the missing dose relative effect of Ginger on loco-motor activity, a synchronic comparison of different types of known antidepressants and the missing assessment of the biochemistry effect of Ginger on vital organs were the limitations observed in this study. We had tried to study an effective and easy obtained herbal substance to evaluate its protective efficacy against electromagnetic fields that enveloped us in everyday life. We suggest more study on known herbal medicine drugs with more details in that field .We cannot stop expansion of technology associated with EMF, but we can protect ourselves, especially young persons, against hazardous effects of radiations. 


\section{CONCLUSION :}

Ginger powder acted as an antidepressant agent (by decreasing anhedonia and increasing locomotors) in vital subjects without or at least with fewer side effects compared with some known pharmaceutical agents, and was more pleasurable to patients.

\section{Acknowledgments:}

We gratefully thank for Clinical PsychiatryResearch Center, Tabriz University of Medical Sciences. Tabriz, Iran for help and financial support.

Figure 1. Effect of $1.5 \mathrm{~g} / \mathrm{kg}$ body weight Ginger rhizome and $50 \mathrm{~Hz}$ EMF on forced swimming test parameters in the 2 nd week.

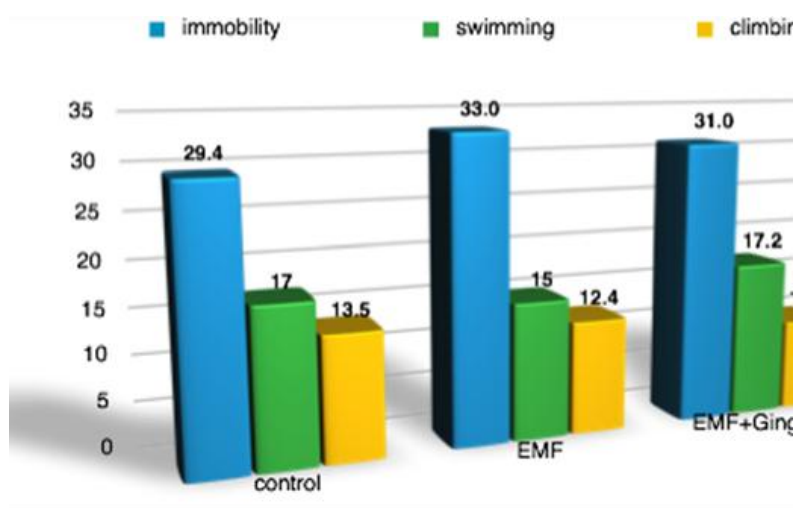

Figure 2. Effect of $1.5 \mathrm{~g} / \mathrm{kg}$ body weight Ginger rhizome and $50 \mathrm{~Hz}$ EMF on forced swimming test parameters at the end of 8th week.

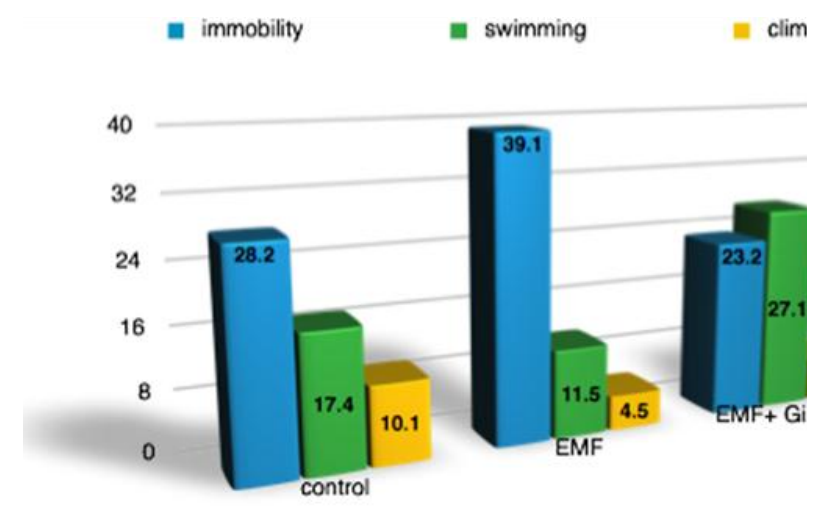




\section{References:}

1.Croft RJ, Chandler JS, Burgess AP, Barry RJ, Williams JD, Clarke AR. Acute mobile phone operation affects neural function in humans. Clin Neurophysiol. 2002; 113(10):1623-1632.

2. Hamblin DL, Wood AW. Effects of mobile phone emissions on human brain activity and sleep variables. Int. J. Radiat. Biol. 2002; 78(8): 659- 669.

3. Gül.in I, Elmastas M, Aboul-Enein HY. Determination of antioxidant and radical scavenging activity of Basil (Ocimum basilicum L. Family Lamiaceae) assayed by different methodologies. Phytother. Res. 2007; 21(4): 354-361

4. Katalinic V, Kulisic T, Milos M, Jukic M. Screening of 70 medicinal plan extracts for antioxidant capacity and total phenols. Food chemistry 2006; 94(4):550-557

5. Khaki A, Fathiazad F, Nouri M, Khaki A. A, Ozanci C. C, Ghafari-Novin M, Hamadeh, M. The effects of Ginger on spermatogenesis and sperm parameters of rat. IJRM. 2009; 7(1): 7-12.

6. Detke MY, Johnson J, Lucki I. Acute and chronic antidepressants during treatment in the rat forced swimming test model of depression. Exp. Clin. Psychopharm. 1997; 5(2): 107-112.

7. Urigüen L, Arteta D, Díez-Alarcia R, Ferrer-Alcón M, Diaz A, Pazos A, et al. Gene expression patterns in brain cortex of three different animal models of depression. Genes. Brain and Behavior. 2008; 7(6): 649-658.

8. Cryan JF, Markou A, lucki I. Assessing antidepressant activity in rodents: recent developments and future needs. Trends Pharm. Sci. 2002; 23(5): 238-245.

9. Porsolt RD, Bertin A, Jalfre M. Behavioral despair in Mice: a primary screening test for antidepressants. Arch. Int. Pharmacodyn. Ther. 1977; 229 (2): 327-336.

10. Porsolt RD, Anton G, Blavet N, Jalfre M. Behavioral despair in rats: A new model sensitive to antidepressant treatment. Eur. J. Pharm. 1978; 47(4) : 379-391.

11. Cryan JF, Valentino RY, Lucki I. Assessing substrates underlying the behavioral effects of antidepressants using the modified rat forced swimming test. Neurosci. Biobehav. Rev. 2005; 24(4-5): 547-569.

12. Page ME, Detke MJ, Dalvi A, Kirby JG, Lucki I. Serotoninergic mediation of the effects of fluoxetine, but not desipramine, in the rat forced swimming test. Psychopharmacology. 1999; 147(2): 162-167.

13. Garcia-Garcia P, Lopez-Munoz F, Rubio G, Martin-Agueda B, Alamo C. Phytotherapy and psychiatry: bibliometric Study of the scientific literature from the last 20 years. Phytomedicine. 2008; 15: 566-576. 
14. Toda M, Morimoto K. Effect of lavender aroma on salivary endocrinological stress markers. Arch. Oral. Biol. 2008; 53(10): 964-968.

15. Panossian A, Nikoyan N, Ohanyan N, Hovhannisyan A, Abrahamyan H, Gabrielyan E, et al. Comparative study of Rhodiola preparations on behavioral despair of rats. Phytomedicine 2008; 15 (1): 84-91.

16. Limpeanchob $\mathrm{N}$, Jaipan $\mathrm{S}$, Rattanakaruna $\mathrm{S}$, Phrompittayarat $\mathrm{W}$, Ingkaninan $\mathrm{K}$. Neuroprotective effect of Bacopa monnieri on beta-amyloid-induced cell death in primary cortical culture. J. Ethnopharm. 2008; 120(1): 112-117.

17. Sarris J, Kavanagh DJ. Kava and St John's wort: current evidence for use in mood and anxiety disorders. J. Altern. Compl. Med. 2009; 15(8): 827-836.

18. Hosseinzadeh H, Noraei NB. Anxiolytic and hypnotic effect of Crocus sativus aqueous extract and its constituents, crocin and safranal, in mice. Phytother. Res. 2009; 23(6): 768-774.

19. Krishnakumar A, Nandhu MS, Paulose CS. Upregulation of 5-HT2C receptors in hippocampus of pilocarpine-induced epileptic rats: antagonism by Bacopa monnieri. Epilep. Behav. 2009; 16(2): 225-230.

20. Awad R, Muhammad A, Durst T, Trudeau VL, Arnason JT. Bioassay-guided fractionation of lemon balm (Melissa officinalis L.) using an in vitro measure of GABA transaminase activity. Phytother Res. 2009; 23(8): 1075-1081.

21. Lopez V, Martin S, Gomez-Serranillos M.P, Carretero ME, Jager AK, Calvo MI. Neuroprotective and neurological properties of Melissa officinalis. eurochem. Res. 2009; 34(11): 1955-1961.

22. Grundmann O, Wahling C, Staiger C, Butterweck V (2009). Anxiolytic effects of a passion flower (Passiflora incarnata L) extract in the elevated plus maze in mice. Pharmazie 2009; 64(1): 63-64.

23. Cao JX, Zhang QY, Cui SY, Cui XY, Zhang J, Zhang YH, et al. Hypnotic effect of jujubosides from Semen Ziziphi Spinosae. J. Ethnopharm. 2010; 130(1): 163-166.

24. Cho SM, Shimizu M, Lee CJ, Han DS, Jung CK, Jo JH, Kim YM. Hypnotic effects and binding studies for GABA (A) and 5-HT (2C) receptors of traditional medicinal plants used in Asia for insomnia. J. Ethnopharm. 2010; 132(1): 225-23

25. Chang Y, Wang SJ. Hypericin, the active component of St. John's wort, inhibits glutamate release in the rat cerebrocortical synaptosomes via a mitogen-activated protein kinasedependent pathway. Eur. J. Pharm. 2010; 634(1): 53-61.

26. Sarris J, Kavanagh D, Byrne G . Adjuvant use of nutritional and herbal medicines with antidepressants, mood stabilizers and benzodiazepines. J. Psychiatr. Res. 2010; 44(1): 32-41.

27. Kasper S, Volz HP, Moller HJ, Dienel A, Kieser M. Continuation and long-term maintenance treatment with Hypericum extract WS 5570 after recovery from an acute episode 
of moderate depression - a double-blind, randomized, placebo controlled long-term trial. Eur.Neuropsychopharm. 2008; 18(11): 803-813.

28. Kasper S, Gastpar M, Moller HJ, Muller WE, Volz HP, Dienel A, et al. Better tolerability of St. John's wort extract WS 5570 compared to treatment with SSRIs: a reanalysis of data from controlled clinical trials in acute major depression. Int. Clin. Psychopharm. 2010; 25(4): 204213.

29. Rojecky LB, Kalodera, Samarzija I. The antidepressant activity of Hypericum perforatum L. measured by two experimental methods on mice. Acta. Pharm. 2004; 54(2): 157-162.

30. Ishola IO, Ashorbi RB, Adeoluwa O. Evaluation of anti stress potential and phytochemical constituents of aqueous root extract of Alchornea Cordifoli. Asian. J. Sci. Res. 2008; 1(4): 476480 .

31. Hosseinzadeh H, Motamedshariaty V, Hadizadeh F. Antidepressant effect of Kaemperol, a constituent of Saffron (Crocus Sativus) petal, in mice and rats. Pharmacologyonline. 2007; 2: $367-370$

32. Phuong M, Nguyen-Emily D, Niemeyer. Effects of Nitrogen Fertilization on the Phenolic Composition and Antioxidant Properties of Basil (Ocimum basilicum L). J. Agric. Food Chem. 2008; 56(18): 8685-8691.

33. Shahidi F, Janitha PK, Wanasundara PD . Phenolic antioxidants. Critical Rev. Food Sci. Nutr. 1992; 32(1): 67-103 